\title{
DESIGUALDADE E POBREZA: Lições de Sen
}

\section{Celia Lessa Kerstenetzky}

A escolha de Amartya Kumar Sen para receber o prêmio Nobel de Economia de 1998 não suscitou grande comoção na academia, tendo sido amplamente prevista e, salvo engano, bem acolhida. Se despertou pouca surpresa, tampouco produziu maiores reflexões.

Confessando desde já minha inapetência para tentar discernir tanto as razões da Academia sueca quanto as crenças dos que as anteciparam, gostaria apenas de romper a inércia que costuma seguir-se à unanimidade e propor algumas reflexões sobre a contribuição de Sen. Não sei se terão sido os motivos que encontrei os mesmos que levaram ao amplo reconhecimento de sua obra, mas espero que, uma vez articulados, a simpatia em relação a ela siga sendo ao menos tão intensa. Minha percepção é que a preocupação com a pobreza e a desigualdade orientou profundamente a obra de Sen, conduzindo a desenvolvimentos em várias direções e em grande profusão; por inadequação dos instrumentos que encontrava, Sen teria sido igualmente levado a produzir ou refinar muitas das ferramentas analíticas que utiliza. 0 resultado é uma obra de ecrivain engagé, de amplo espectro e grande refinamento, que nos faz pensar produtivamente, e não apenas lamentar, os limites da especialização e da fragmentação do conhecimento.

Este é um texto preliminar que, não tendo a pretensão de ser exaustivo ou sistemático, resulta de um contato de longa data com vários livros e artigos de Sen, contato que agora se precipita em um certo aprendizado. As "lições" recolhidas, e que gostaria de compartilhar, acham-se agrupadas em três seções, onde discuto as relações entre: (1) Economia e ética; (2) ética e racionalidade; e (3) desigualdade e pobreza. A seção final traz algumas considerações gerais, tecidas à luz das discussões precedentes.

\section{Economia e ética}

Após a conhecida fórmula de Gary Becker (1976), sabe-se que os economistas teóricos são aquelas pessoas que discernem 0 mundo através das lentes do método de otimização ${ }^{1}$ e não, como durante anos e talvez séculos chegou-se a pensar, aqueles cientistas sociais que estudavam a esfera da produção e da distribuição de bens materiais. 0 Nobel de 1992 assevera que a Economia se caracteriza pelo método e não pelo tema, ele mesmo tendo conduzido a Economia assim redefinida a 
entender o crime, os casamentos e divórcios, a guarda dos filhos, as relações entre pais e filhos, e uma variedade infindável de problemas. Amparados pelas razões fornecidas por Becker, os economistas passaram a aplicar, aparentemente com maior legitimidade, o mesmo método a vários temas, em virtude do que a Sociologia, a Psicologia, a Política (rebatizada de Economia Política Positiva), o Direito e a Antropologia transmudamse gradualmente em áreas de especialização econômica.

Ora, nessa perspectiva beckeriana de "um método, todos os temas", cuja semelhança com 0 marxismo deve ser notada, Amartya Sen afigura-se um economista sui generis em sua insistência quanto às relações íntimas entre a Economia e a ética, ao mesmo tempo em que pratica e, por fim, explicita um saudável pluralismo de método (que não o identifica coerentemente nem com a ortodoxia, nem com a heterodoxia na Economia). Um tema de base, vários métodos. Se a análise econômica, na sugestão de Becker, promove o que poderíamos chamar de interdisciplinaridade à força, já que se trata da superimposição de uma visão de mundo a diferentes configurações do mundo, 0 feito de Sen sugere uma versão relativa de interdisciplinaridade em que se reconhece a pertinência de cada plano discursivo e se indica as relações de fertilização recíproca possíveis.

Se a Economia é o saber sobre as relações humanas voltadas para a produção e distribuição da riqueza material, a riqueza, entretanto, nos interessa principalmente como instrumento de bem-estar, por sua vez parte de uma visão mais ampla dos propósitos humanos. ${ }^{2}$ Trata-se aqui de uma hierarquia em que a dimensão ética tem clara precedência, ou melhor, é a dimensão envoltória: Sen nos propõe uma visão dos propósitos humanos que não se detenha no espaço do "ter", abrangendo o "fazer" (doings) e o "ser" (beings) - algo que, conforme veremos na terceira seção deste artigo, corresponde à idéia de "funcionamentos" (functionings). Entretanto, teres, fazeres e seres são importantes não tanto em si mesmos mas como indicadores da liberdade efetiva dos indivíduos - que corresponde, como veremos, à noção de "capacidades" (capabilities).
Sen aqui é um leitor atento da tradição liberal clássica, tanto da economia política quanto da filosofia política. Mas também é alguém especialmente sensível às peculiares formas de destituição e exclusão, e às profundas desigualdades que comprimem, quando não anulam, as liberdades efetivas em um mundo onde enormes progressos materiais foram alcançados.

Dado que a dimensão ética projeta uma sombra sobre a Economia, sugerindo uma reflexão sobre os fins últimos da atividade econômica em uma sociedade, ela interrompe qualquer automatismo que se possa atribuir a esta esfera. Como distribuir a riqueza gerada de modo a se alcançar 0 objetivo de ampliação das liberdades efetivas? Como conciliar os imperativos da justiça (não apenas como eqüidade, mas como ampliação de liberdades) com os da eficiência econômica (e Sen não parece ser insensível à necessidade de se qualificar 0 famoso tradeoff entre eficiência e igualdade)? Ora, é justamente no não reconhecimento dessa autonomia do econômico em seu próprio terreno, na percepção de uma constante necessidade de avaliação dos processos de geração e divisão da riqueza que reside 0 mais forte apelo à cooperação interdiscursiva entre 0 raciocínio ético e 0 raciocínio econômico.

Mas, também no interior mesmo da Economia descritiva e preditiva Sen acredita na proficuidade do intercâmbio com a ética. Qual o papel de supostos de comportamento alternativos ao autointeresse na teoria econômica? Certamente produtivo, uma vez que a Economia teria muito a ganhar em relevância se suplementasse 0 suposto do comportamento auto-interessado com outras motivações, como o comportamento não voltado estritamente para o bem-estar pessoal, ou se incorporasse uma noção de bem-estar mais abrangente que o consumo pessoal, ou mesmo o comportamento não estritamente orientado por objetivos, como o guiado por regras convencionais. 0 suposto restritivo de comportamento auto-interessado estaria afetando não apenas a relevância da teoria econômica positiva como também a de seu afluente normativo, a economia do bem-estar.

Em seu On ethics and economics, de 1988, que ganha agora uma tradução para 0 português 
(Sen, 1999), Sen se estende sobre as relações naturais e separações forçadas entre Economia e ética, sugerindo que ambos os campos discursivos teriam muito a ganhar se reconhecessem os rendimentos óbvios da cooperação. Entretanto, o argumento concentra-se mais nas perdas para a Economia decorrentes de sua incapacidade de reconhecer estes ganhos. Por um lado, observa-se o empobrecimento da economia do bem-estar quando expulsa as comparações interpessoais de vantagens para o terreno da ética e quando reduz a avaliação de estados sociais alternativos ao bemestar dos indivíduos e o confina à satisfação de suas preferências. Por outro, percebe-se 0 baixo índice de relevância da economia positiva decorrente da imaginação rarefeita no desenho de hipóteses comportamentais, usualmente mais servis ao crité rio de consistência. De um modo geral, sobressai o tratamento meramente instrumental e caricato das motivações possivelmente éticas. Perdas para a ética também são mencionadas, porém com ligeireza; a mais importante seria o reconhecimento da importância do raciocínio conseqüencialista em questões típicas do campo da ética, tais como 0 tratamento interativo dos direitos e das liberdades, que emerge da igualmente significativa, e fartamente analisada pelos economistas, interdependência social e cuja representação analítica se pode encontrar nos modelos de equilíbrio geral. Porém, sabe-se que a análise conseqüencialista não é invenção da Economia, e tampouco a idéia de interdependência social. Pode-se, portanto, compreender as razões da brevidade na argumentação quanto aos ganhos da mão inversa. ${ }^{3}$

Evidentemente, Sen não ignora uma certa concepção, freqüente na Economia, de que toda e qualquer motivação pode ser incorporada no autointeresse dos indivíduos, inclusive suas motivações morais e o seguir regras. Qualquer uma destas coisas poderia ser compreendida como o objetivo que 0 indivíduo quer maximizar. Analisando uma possível racionalidade alternativa, não voltada para objetivos individuais e que poderia dar conta de comportamentos cooperativos em jogos nãocooperativos, Sen observa que o comportamento cooperativo poderia emergir como efeito do reconhecimento, por parte dos indivíduos, da interde- pendência de seus ganhos. Neste caso, seguir certas regras de comportamento (como a de reciprocidade) pode ser a estratégia a adotar, em razão de sua importância instrumental para a promoção dos objetivos de cada um. Dizer, então, que seguir as regras foi o objetivo dos indivíduos é no mínimo ambíguo: "Se a reciprocidade não é considerada importante intrinsecamente e sim instrumentalmente, e esse reconhecimento se expressa de fato em comportamento recíproco para melhor atingir os objetivos de cada pessoa, é difícil argumentar que o 'objetivo real' da pessoa é seguir a reciprocidade em vez de seus respectivos objetivos reais." (Sen, 1999, p. 102). ${ }^{4}$

\section{Ética e racionalidade}

Em sua crítica à dieta auto-imposta à Economia por seu afastamento da ética, Sen queixa-se da noção excessivamente restritiva de racionalidade utilizada pela disciplina. De um modo geral, a racionalidade economista ou impõe consistência interna às escolhas sem pronunciar-se sobre 0 conteúdo destas escolhas, ou se manifesta como a busca pela maximização do auto-interesse, adotando neste caso uma posição demasiado simplificadora em relação às motivações dos indivíduos. É necessário, diz ele, reconhecer a existência tanto de outras motivações quanto de outras definições de racionalidade que ultrapassem a exigência de consistência interna da escolha. Esta necessidade adviria do imperativo da relevância de nossas explicações, bem como da praticidade das prescrições de políticas públicas.

0 resultado destas objeções seria a incorporação de motivações, por exemplo, morais na E conomia, e de um modo mais amplo, implicaria a investigação do conjunto de valores que os indivíduos procuram realizar, bem como a admissão da possibilidade de "inconsistências" na escolha, na forma de incompletude, ou ao menos de completude parcial das ordenações de valores por parte dos indivíduos. Pluralismo de valores e um racionalismo formal mitigado são as idéias centrais que orientam as relações entre ética e racionalidade, gerando implicações importantes no campo da ética. Gostaria de chamar a atenção para alguns 
aspectos significativos das relações entre esta proposta e as principais correntes contemporâneas de teoria normativa, o utilitarismo e 0 rawlsianismo, ${ }^{5}$ adiantando que a maior dificuldade com estes sistemas de filosofia moral encontra-se em sua excessiva ambição universalista.

A objeção maior de Sen ao utilitarismo devese à ênfase deste último no bem-estar, ao que ele chama de aspecto welfarista do utilitarismo, ${ }^{6}$ que padeceria de injustificado reducionismo de valor. Adicionalmente, ao apoiar-se na utilidade e nas preferências dos indivíduos, o utilitarismo não faria justiça às óbvias assimetrias de informação e de condição existentes entre eles, as quais permitem que alguns tenham preferências "caras" enquanto outros formem, resignadamente, preferências "baratas". Na economia do bem-estar, o welfarismo do utilitarismo encontraria expressão no critério de ótimo de Pareto, que justamente por basear-se em utilidades, e conseqüentemente em preferências, revelar-se-ia um critério além de insuficiente, informacionalmente inadequado para a avaliação de estados sociais alternativos. 0 utilitarismo distorceria a avaliação dos estados sociais possíveis sobretudo ao sancionar, de um lado, o conformismo daqueles que sofrem opressão e discriminação sociais continuadas, e que ajustariam suas preferências às suas minguadas possibilidades de realização, e de outro, os privilégios de elites que já deitaram raízes.

Quanto ao rawlsianismo, em relação ao utilitarismo apresentaria a vantagem de propor uma visão mais plural de valor, expressa na categoria de bens sociais primários, cujo propósito seria captar a dimensão de liberdade real que os indivíduos possuem em uma sociedade para realizar suas diferentes concepções de vida, e cuja distribuição deve ser 0 mais igualitária possível (ver Rawls, 1971). Fracassaria, entretanto, na capacidade de dar expressão ao déficit de liberdade efetiva dos indivíduos desfavorecidos que estiveram expostos à condição de destituição continuada ou à incapacidade física ou mental. A igualdade na distribuição de bens primários não atenderia a estes possuidores de carências especiais que, em relação aos demais, apresentam diferenciadas e desfavoráveis taxas de conversão de bens primários em liberda- des efetivas; a demanda por eqüidade não satisfaria a demanda por justiça.

Ademais, pode-se dizer que a ambição de se construir um sistema de filosofia moral baseado em um único valor como o bem-estar, assim como a de se encontrar um procedimento eqüitativo para a distribuição de meios plurais para a realização de uma pluralidade de valores, são extremamente exigentes quanto à capacidade racional dos indivíduos em reconhecer estes valores ou este procedimento como aqueles que se deve seguir. É aqui que entra 0 que chamei de racionalismo formal mitigado de Sen.

Trata-se principalmente da saudável admissão, por parte de Sen, da existência de conflitos de valor ou dilemas morais. Na construção de uma função utilidade ou do índice rawlsiano de bens primários, a hierarquia de valores não é problemática: no caso utilitarista, há apenas o bem supremo da utilidade; na vertente rawlsiana há uma ordenação lexicográfica entre os bens primários correspondente à ordenação entre os dois princípios de justiça e suas divisões internas. Sen recupera a discussão clássica dos dilemas morais, freqüentes, por exemplo, na tragédia grega (como nos recordam os dilemas de Agamenon e Antígona) e certamente relevantes para se entender uma variedade de problemas de escolha. Incorpora, em conseqüência, as contribuições contemporâneas sobre 0 problema das escolhas dilemáticas de autores como Isaiah Berlin (1978), Stuart Hampshire (1982), Bernard Williams (1981), Thomas Nagel (1979), bem como os trabalhos de Calabresi e Bobbitt (1978) e de Isaac Levi (1986). ${ }^{7}$

A impossibilidade de hierarquização intrapessoal completa de valores sugerida por estes pluralistas (de quem não se pode, contudo, dizer que sejam subjetivistas ou relativistas éticos), indicando limites para a ambição de universalização da moralidade, não impede Sen de perseverar na busca de fundamentos éticos para a legitimação da ação do Estado via políticas públicas. A impossibilidade de se produzir ordenações completas de valores e das ações correspondentes nos deixa 0 second-best de buscar construir ordenações parciais, que podem pragmaticamente funcionar. Se de todo não for possível comparar duas ações que 
nos parecem boas, ou seja, se não for possível encontrar a melhor entre elas ou mesmo afirmar que somos indiferentes entre elas, isto pode representar um problema formal interessante de incomensurabilidade de valores (ou, mais fracamente, de incomparabilidade). 0 que nos conduziria a explorar soluções analíticas menos elegantes do que a completude e a consistência, como a completude parcial ou a "inconsistente" supercompletude. Mas não deveria nos paralisar como fez ao asno de Buridan que, encontrando-se incapaz de decidir qual entre dois montes de feno seria superior, morreu de inanição.

A ação independe de uma resposta unívoca para a pergunta "qual a melhor alternativa?". É claro que o problema da justificação permanece, mas é preciso reconhecer que em muitas situações esta permanecerá incompleta, enquanto decisões serão tomadas. 0 pragmatismo da teoria normativa de Sen parece ainda sugerir a recuperação da importância prática da teoria social no auxílio à solução de dilemas e conflitos, que, neste contexto, encontra-se para os sistemas de filosofia moral assim como 0 contingente encontra-se para 0 universal.

\section{Desigualdade e pobreza}

A contribuição de Sen no domínio dos problemas da desigualdade e pobreza estende-se desde os aspectos conceituais e de mensuração aos de políticas públicas. Em seu On economic inequality, de 1973, Sen debruça-se sobre a questão da medida da pobreza e da desigualdade. Mais tarde, retoma o argumento deste pequeno livro em uma empreitada mais abrangente onde examina em profundidade os aspectos conceituais ligados à definição de desigualdade, sendo a pobreza um dos subtemas de seu livro Inequality reex amined (1992). Em 1997, publica uma extensão de 0n economic inequality. Seu trabalho sobre pobreza é no mínimo igualmente prolixo e remonta pelo menos aos anos 60. De fato, os dois temas aparecem freqüentemente interligados, 0 que tem provocado a afirmação, por parte de alguns críticos, da precedência da temática da pobreza sobre a desigualdade em sua obra, que poderia ser atestada pelo fato de que quando se refere a desigualdades Sen está de fato aduzindo argumentos e evidências relativos à pobreza. Sua insistência nos fenômenos da destituição e da incapacidade física e mental, inclusive como pedras de toque de investidas normativas contemporâneas, aparentemente indicaria 0 acento sobre 0 problema da exclusão social em detrimento do tema das disparidades entre indivíduos e grupos sociais.

Minha percepção, entretanto, é outra. Creio que as contribuições mais significativas de Sen ao debate sobre desigualdade e pobreza são, em primeiro lugar, a dimensão de avaliação dos estados sociais em termos dos seres e fazeres, e do espaço aberto aos indivíduos para escolher entre seres e fazeres alternativos, isto é, em termos dos funcionamentos e capacidades dos indivíduos para levarem adiante seus planos de vida. Esta dimensão avaliatória representaria 0 grau de liberdade efetivamente gozado pelos indivíduos em uma sociedade, segundo a ética do desenvolvimento de Sen. Em segundo lugar, penso que Sen elabora, para além de uma noção de pobreza absoluta - que corresponderia ao alcance de uma condição de vida abaixo do mínimo fisicamente adequado, conceito mais biológico do que social -, uma noção de pobreza relativa. Esta seria afetada pelo nível de desigualdade socioeconômica prevalecente em uma sociedade, e as noções de funcionamentos e capacidades estariam aptas a aferi-lo. Vamos começar pelo exame da dimensão avaliatória proposta.

Em suas Tanner lectures de 1985 (Sen, 1990), sobretudo na segunda conferência, Sen busca formular a agenda positiva de sua discussão sobre o padrão de vida como expressão das condições de vida dos indivíduos. Ele o faz após haver descartado, na primeira conferência, a noção de padrão de vida como opulência ou riqueza, ou ainda como utilidade, quer no sentido de prazer, satisfação do desejo ou escolha, tendo em vista 0 argumento central que norteia sua rejeição ao utilitarismo bem como a uma abordagem economicista da escolha social e do bem-estar, qual seja: ademais de seu injustificado reducionismo valorativo, o problema óbvio de dissonância cognitiva (preferências caras e baratas) que todas 
estas abordagens endossariam de maneira acrítica. Precisamos, diz ele, redefinir os objetos de valor de modo a minimizar os problemas de um subjetivismo radical tal como o utilitarista, que apresenta distorções óbvias. O argumento, que reaparece inúmeras vezes ao longo de sua obra e se reveste de crescente refinamento retórico e impressionante permanência substantiva, é assim expresso na segunda conferência Tanner:

Os fracassados e os oprimidos acabam por perder a coragem de desejar coisas que outros, mais favoravelmente tratados pela sociedade, desejam confiantemente. A ausência de desejo por coisas além dos meios de que uma pessoa dispõe pode refletir não uma valoração deficiente por parte dela, mas apenas uma ausência de esperança, e o medo da inevitável frustração. O fracassado enfrenta as desigualdades sociais ajustando seus desejos às suas possibilidades. (Sen, 1990, pp. 10-11)

À unicidade valorativa que encontra no utilitarismo e na economia do bem-estar de um modo geral, Sen contrapropõe, em sua abordagem dos funcionamentos e capacidades, uma pluralidade de objetos de valor, afirmando que o que tem valor para nós é constitutivamente plural, refletindo a pluralidade possível de seres e fazeres em consonância om a diversidade das carências dos indivíduos. Ademais, estes objetos de valor seriam medidos por meio de ordenamentos parciais, admitindo-se a não rara ocorrência de comensurabilidade apenas parcial entre os diferentes funcionamentos e as diferentes capacidades.

A noção de funcionamentos como os objetos de valor na avaliação das condições de vida dos indivíduos em uma sociedade encontra precursores em Aristóteles, William Petty, Adam Smith, Lagrange e uma vasta tradição da economia política moderna. 0 objeto de investigação parece localizar-se nas condições e tipos de vida que 0 acesso a diferenciados meios, econômicos mas não exclusivamente, seria capaz de proporcionar. Esta investigação requer ir além dos indicadores estritamente econômicos, como os do crescimento do produto e da renda. De fato, Sen reconhece em análises recentes uma ênfase crescente na avaliação das necessidades básicas, incluindo renda, saúde, educação, expectativa de vida, e na construção de indicadores sociais que transcendem 0 indicador de renda. Temos aqui o deslocamento valorativo do espaço do ter para o do fazer e, mais abrangentemente, 0 do ser:

A questão central é a qualidade da vida que podemos levar. A necessidade de possuir mercadorias para que se alcance um determinado patamar de condições de vida varia grandemente segundo características fisiológicas, sociais e culturais, além de outras igualmente contingentes [...] O valor do padrão de vida repousa na vida, e não na possessão de mercadorias, a qual tem relevância derivada e variável. (Sen, 1990, p. 25)

O motivo deste deslocamento está, pois, esclarecido justamente pela contingência e variabilidade sociais e naturais, que respondem pela diferenciação das carências entre indivíduos e grupos. Segundo Sen, ele terá sua melhor representação no espaço dos funcionamentos - os seres e estares e fazeres que os indivíduos podem realizar: "Os funcionamentos [...] podem variar daqueles mais elementares, como estar bem nutrido, escapar de morbidade e mortalidade prematura evitáveis etc., a realizações bastante complexas e sofisticadas, como possuir auto-respeito, ser capaz de tomar parte na vida da comunidade, e assim por diante." (Sen, 1992, p. 5). As capacidades, por sua vez, refletiriam as oportunidades de escolha por diferentes conjuntos de funcionamentos que estariam abertas aos indivíduos, representando a extensão de sua liberdade efetiva, e não apenas, como no índice rawlsiano dos bens sociais primários, os meios para a liberdade, que em princípio seriam insensíveis à variabilidade interpessoal de carências, à sua duração e intensidade.

Para encerrar esta breve apresentação da contribuição de Sen no que respeita ao espaço de avaliação, deve-se notar que a avaliação em termos de funcionamentos e capacidades estaria apta a representar três níveis de objetivos das pessoas: seu padrão de vida (standard of living), seu bemestar pessoal (well-being) e seus objetivos como 
agência (agency). $\mathrm{O}$ indivíduo pode ser visto, multidimensionalmente, ${ }^{8}$ como alguém que possui ambições que dizem respeito às suas condições pessoais de vida e que não envolvem expectativas quanto às condições de vida de outros (por exemplo, respirar 0 ar puro da montanha nos fins de semana); que possui ambições que podem envolver as condições de vida ou o bem-estar de outras pessoas, a simpatia podendo ser incluída como um aspecto de seu bem-estar pessoal (por exemplo, levar a família para respirar o ar puro da montanha nos fins de semana); e, finalmente, como alguém que possui compromissos que envolveriam a realização de objetivos que devem ser perseguidos independentemente de seus efeitos sobre seu bem-estar pessoal (por exemplo, em suas horas de lazer, militar em movimento em defesa da preservação do meio ambiente em uma poluída megalópole). Correspondentemente, podemos pensar estes diferentes aspectos e objetivos em termos de funcionamentos e capacidades.

Passemos agora ao exame da conexão entre pobreza e desigualdade que, creio eu, indica uma importante contribuição de Sen. De novo, a fonte é a economia política, Adam Smith em particular, de quem Sen extrai a importante capacidade de "poder apresentar-se em público sem sentir vergonha". Distinguindo os funcionamentos e as capacidades biológica e universalmente determinados daqueles que 0 são socialmente, isto é, que dependem de um padrão médio efetivamente alcançado por uma comunidade, Sen invoca Smith para lembrar que

[p]ara levar a vida sem sentir vergonha, para ser capaz de visitar e cultivar amigos, para manter-se a par do que está acontecendo e sobre o que os outros estão falando, e assim por diante, é preciso um conjunto mais caro de bens e serviços em uma sociedade geralmente mais rica, e na qual um grande número de pessoas tem, digamos, meios de transporte, vestimenta adequada, aparelhos de rádio e televisão etc. (Sen, 1990, p. 18)

Neste caso, a pobreza relativa ganha grande relevância. 0 reconhecimento da relatividade social e cultural das necessidades parece conectar as realizações de uns ao que outros conseguem alcançar, reduzindo ou eliminando os sentimentos de vergonha e baixa estima resultantes de uma comparação sempre desfavorável com os mais bem situados. E os fatos sociológicos da eventual invisibilidade destas diferenças, e seu confinamento em grupos de referência, não devem impedir 0 exame crítico da justeza destas situações.

\section{Comentários finais}

Uma estratégia argumentativa algo freqüente sobretudo nos textos menos técnicos de Sen é minimizar as diferenças entre as suas contribuições e a dos contemporâneos seus com quem dialoga. É assim quando, em seu Inequality reexamined, Sen reúne os utilitaristas, os libertarianos e os contratualistas na mesma comunidade de igualitaristas, mais ou menos autoconscientes de seu igualitarismo. Neste mesmo volume, Sen reconhece sua enorme dívida intelectual com John Rawls, de cuja concepção de justiça se diz adepto, sugerindo apenas alterações no equalisandum e fornecendo razões aparentemente secundárias para estes reparos que não atingiriam 0 edifício da construção rawlsiana. Também este parece ser 0 caso no que diz respeito a contribuições à economia do bem-estar e à discussão do problema da racionalidade em Economia: Sen entra no barco da economia do bem-estar, e em particular no debate da teoria da escolha social pós-Arrow, com intervenções pouco ortodoxas (como a crítica aos fundamentos do critério de Pareto e a formulação do paradoxo do liberal paretiano, em Sen (1970), assim como no debate em torno da noção de racionalidade econômica com os seus "tolos racionais" (Sen, 1977) e a crítica nada lateral ao suposto comportamental do auto-interesse, como se fossem apenas extensões não problematicamente incorporáveis ao mainstream da literatura. Penso que esta atitude seja uma socrática afetação de modéstia, amparada na aristotélica sabedoria de acomodar as diferenças em diferentes dimensões para dissolver as antinomias, que mal esconde uma dissensão e um poder de fogo consideráveis.

De fato, sob certos importantes aspectos, sua obra não se confunde com a de seus interlocutores 
mais próximos, constituindo, de um modo geral, uma altemativa original. Assim, podemos dizer que sua reflexão sobre a pobreza e a desigualdade manteve-se a meio caminho entre a teoria normativa pura e a análise sociológica contemporânea, ${ }^{9}$ 0 que se reflete nos conceitos elaborados, os quais buscam capturar dimensões sociológicas que trazem à tona aspectos contingentes do mundo social que não podem ser considerados (de fato, têm de ser sistematicamente abstraídos) pelas teorias normativas puras: os tipos sociológicos dos subnutridos, dos mórbidos, dos deficientes físicos e mentais; as grávidas, os idosos, os pobres, os miseráveis, as classes sociais, as mulheres e os homens, as raças, as castas, verdadeiro mosaico sociológico a tomar complexo o raciocínio normativo, a qualificar a avaliação quanto à justeza dos estados sociais. Teremos de elaborar sozinhos - pois aqui Sen nos abandona - a conciliação possível entre a eqüidade rawlsiana e a discriminação positiva aparentemente sugerida por ele, bem como a suspensão do véu de ignorância. Mas, seguramente, a visão de Sen é mais subjetivista do que a de Rawls, e mesmo sua ambição de universalismo mais tímida, admitindo uma relatividade posicional e métodos de avaliação relativos às posições dos indivíduos. ${ }^{10}$

Não obstante, Sen nitidamente se distancia do subjetivismo utilitarista, elitista e conformista (recordar o problema de dissonância cognitiva das preferências "baratas"). Para Rawls, o princípio utilitário esbarra no problema da responsabilidade: pessoas racionais têm de ser capazes de revisar suas demandas por bens primários tendo em vista a razoabilidade destas, e aqui Rawls tem em mente sobretudo 0 problema das preferências caras. Esta crítica aparentemente se aplicaria também à consideração por Sen das variações interindividuais e sua afirmação de que estas devem ter um peso na avaliação dos estados sociais: para Sen, o mesmo conjunto de bens primários pode representar diferentes extensões de liberdade efetiva para pessoas que sejam, por exemplo, fisiologicamente diferentes ou que apresentem, de modo geral, carências diferenciadas. Teríamos de levar em conta as diferentes taxas de conversão dos bens sociais primários sugeridos por Rawls em realizações e liberdades efetivas: [n]ós diferimos não apenas na riqueza que herdamos, mas também em nossas características pessoais. Além das variações puramente individuais (i.e., habilidades, predisposições, diferenças físicas), há também contrastes sistemáticos entre grupos (por exemplo, entre homens e mulheres em aspectos específicos como a possibilidade de gravidez e os cuidados requeridos pelos recémnascidos). (Sen, 1992, p. 27)

Aqui aparece uma importante diferença entre Rawls e Sen: este se opõe tanto à distorção utilitarista, indiferente às assimetrias do mundo social que levam à formação distorcida de expectativas, quanto à indiferença de Rawls às carências dos especialmente destituídos, em nome da responsabilidade. Sen replica que é possível invocar a responsabilidade pelas escolhas individuais com 0 propósito de temperar as demandas por justiça apenas num mundo contrafactual onde estão plenamente disponíveis o conhecimento e a habilidade das pessoas de entender e escolher inteligentemente a partir das alternativas diante delas (cf. Sen, 1992, p. 149). Entretanto, ante a existência factual de incertezas e sobretudo de formas de condicionamento social que fazem a pessoa perder a coragem de escolher, e mesmo de desejar, qual 0 sentido de imputar a ela a responsabilidade por suas escolhas? A questão relevante parece, implicitamente, ser a seguinte: não estaríamos sobrecarregando em demasia a quantidade de fatos ocultados pelo véu de ignorância, ao mesmo tempo em que estaríamos magnificando as habilidades cognitivas, interpretativas e de discernimento à frente dele? Obviamente, a necessidade de um método objetivo de avaliação é imperiosa, mas Sen parece sugerir que este possa ser encontrado por vias menos excessivamente racionalistas.

0 racionalismo mitigado de Sen rejeita, pois, tanto a concentração extrema em uma visão de racionalidade como consistência interna da escolha e como maximização do auto-interesse, habitual na teoria econômica moderna, quanto o racionalismo contrafactual, igualmente radical, presente nas teorias normativas. Ser racional requereria apenas, à la Bernard Williams (1985), ser capaz de prover razões para a ação ou a inação, que não 
necessariamente precisam obedecer cegamente ao critério de consistência, nem produzir ordenações completas das alternativas que se apresentam. Mas o imperativo da decisão, sobretudo das decisões que envolvem políticas públicas, e dentre elas as comprometidas com a redução da pobreza e da desigualdade no mundo contemporâneo, não precisa esperar pela completude da análise formal que pode paralisar-se diante do problema da incomensurabilidade das alternativas e das escolhas trágicas; pode apoiar-se nas razões contingentes produzidas pelo second-best das ordenações parciais que seremos, em cada caso, capazes de produzir. Ao invés de asnos inteligentes teremos então sido humanos, apenas parcialmente inteligíveis.

\section{NOTAS}

1 Refiro-me, evidentemente, aos economistas do mainstream da ciência econômica.

20 aristotelismo ético que pode ser aqui pressentido é presença constante na cosmologia de Sen, e vem freqüentemente associado ao trabalho de Martha Nussbaum.

3 Devemos recordar que Sen dirige estas suas conferências Royer - que proferiu na Universidade da Califórnia em Berkeley, e que reuniu e publicou em 1988 sob 0 título $0 \mathrm{n}$ ethics and economics - a uma platéia composta também por economistas.

4 Sen retoma a crítica ao reducionismo envolvido nesta concepção de racionalidade em inúmeras passagens de sua obra. É, entretanto, notável o que parece ser uma inflexão em seu pensamento em Sen (1991), onde ele defende a plasticidade do conceito de preferência.

5 Refiro-me à abordagem procedimental de Rawls (1971) na derivação de princípios de justiça.

6 As outras duas características do utilitarismo seriam 0 conseqüencialismo e a ordenação pela soma das utilidades individuais. Ver a formulação original destas idéias em Sen e Williams (1982). O rawlsianismo, por exemplo, seria uma forma de conseqüencialismo não-welfarista, já que os valores são os bens sociais primários e não as utilidades individuais, e os estados sociais seriam julgados não pelo critério de maximização do agregado das vantagens mas sim pela maximização das vantagens em termos de bens sociais primários ordenados lexicograficamente.

7 Berlin aponta a possibilidade de perda moral por conta de conflitos entre valores em que não se pode definir claramente um tradeoff entre eles. Idéia semelhante é desenvolvida em Calabresi e Bobbitt (1978), em sua discussão sobre as escolhas trágicas, e em Levi (1986), onde se desenvolve uma discussão não apenas conceitual mas também técnica do que ele chama de escolhas difíceis.

8 Sen apresenta este argumento extensamente em suas conferências Dewey (Sen, 1985a) e em Sen (1985b).

9 Tenho em mente a literatura anglo-saxônica. Ver, a propósito, Bradley (1996).

10 Ver o argumento por uma objetividadade posicional em Sen (1993).

\section{BIBLIOGRAFIA}

BECKER, G. (1976), The economic approach to human behaviour. Chicago, University of Chicago Press.

BERLIN, I. (1978), Conopts and categories. Oxford, Oxford University Press.

BRADLEY, H. (1996), Fractured identities - changing patterns of inequality. Cambridge, Polity Press.

CALABRESI, G. e BOBBITT, P. (1978), Tragic choices. Nova York, Norton.

HAMPSHIRE, S. (1982), "Morality and convention", in A. Sen e B. Williams (eds.), Utilitarianism and beyond, Cambridge, Cambridge University Press.

LEVI, I. (1986), Hard choios. Cambridge, Cambridge University Press.

NAGEL, T. (1979), Mortal questions. Cambridge, Cambridge University Press.

RAWLS, J. (1971), A theory of justice. Cambridge, Mass., Harvard University Press.

SEN, A. (1970), "The impossibility of a paretian liberal". Journal of Political Economy, 72.

. (1973), On economic inequality. Oxford, Clarendon Press.

. (1977), "Rational fools: a critique of the behavioural foundations of economic theory". Philosophy and Public A ffairs, 6.

. (1985a), "Well-being, agency and freedom: the Dewey lectures 1984". Journal of Philosophy,

82.

. (1985b), "Goals, commitment and identity". Journal of Law, E conomics and Organization, 1. 
(1988), On ethics and economics.

Oxford, Blackwell. . (1990), The standard of living (The Tanner lectures). Cambridge, Cambridge University Press.

(1991), "Welfare, preference and freedom". Journal of E conometrics, 50 (1-2):15-29.

(1992), Inequality reex amined. Nova York, Russel Sage Foundation.

(1993), "Positional objectivity". Philosophy and Public A ffairs, 22 (2).

- (1999), Sobre ética e economia. São Paulo, Companhia das Letras.

SEN, A. e WILLIAMS, B. (1982), Utilitarianism and beyond. Cambridge, Cambridge University Press.

WILLIAMS, B. (1981), Moral luck. Cambridge, Cambridge University Press.

- (1985), E thics and the limits of philosophy. Londres/ Cambridge, Mass., Fontana/ Harvard University Press. 